0-013 THE SMART REGISTRY: FINAL RESULTS ON THE UTILITY OF THE PENUMBRA SMART COIL SYSTEM FOR TREATMENT OF INTRACRANIAL ANEURYSMS AND MALFORMATIONS

${ }^{1} \mathrm{~A}$ Spiotta* ${ }^{2} \mathrm{M}$ Park, ${ }^{3} \mathrm{R}$ Bellon, ${ }^{4} \mathrm{~B}$ Bohnstedt, ${ }^{5} \mathrm{C}$ Schirmer, ${ }^{6} \mathrm{R}$ Deleacy, ${ }^{7} \mathrm{D}$ Fiorella, ${ }^{8} \mathrm{~B}$ Woodward, ${ }^{9} \mathrm{~B}$ Baxter, ${ }^{10} \mathrm{~S}$ Kale, ${ }^{11} \mathrm{O}$ Zaidat, ${ }^{12} \mathrm{P}$ Sunenshine, ${ }^{13} \mathrm{~A}$ Yoo, ${ }^{14} \mathrm{M}$ Kabbani, ${ }^{15} \mathrm{~K}$ Liu, ${ }^{16} \mathrm{R}$ Starke, ${ }^{17} \mathrm{~A}$ Reeves, ${ }^{18} \mathrm{~K}$ Snyder, ${ }^{19} \mathrm{~T}$ Sivapatham, ${ }^{20} \mathrm{~T}$ Dumont. ${ }^{1}$ Dept. of Neurosurgery, Medical University of South Carolina, Charleston, SC; ${ }^{2}$ University of Virginia, Charlottesville, VA; ${ }^{3}$ Swedish Medical Center, Denver, CO; ${ }^{4}$ Oklahoma University Medical Center, Oklahoma City, OK; ${ }^{5}$ Geisinger Medical Center, Danville, PA; ${ }^{6}$ Mount Sinai, New York, NY; ${ }^{7}$ Stony Brook University Medical Center, Stony Brook, NY; ${ }^{8}$ Vista Radiology, Knoxville, TN; ${ }^{9}$ Tennessee Interventional Associates, Chattanooga, TN; ${ }^{10}$ SSM Health St. Clare Hospital, Fenton, MO; ${ }^{11}$ St Vincent Mercy Health Medical Center, Toledo, OH; ${ }^{12}$ Banner University Medical Center, Phoenix, AZ; ${ }^{13}$ Texas Stroke Institute, Plano, TX; ${ }^{14}$ Gundersen Health System, La Crosse, WI; ${ }^{15}$ Penn State Milton S Hershey Medical Center, Hershey, PA; ${ }^{16}$ University of Miami Hospital, Miami, FL; ${ }^{17}$ University of Kansas, Kansas City, KS; ${ }^{18}$ University of Buffalo, Buffalo, NY; ${ }^{19}$ Christiana Care Health System, Newark, DE;

${ }^{20}$ University of Arizona, Tucson, $A Z$

10.1136/neurintsurg-2020-SNIS.13

Introduction The Penumbra SMART COIL ${ }^{\circledR}$ System includes a novel generation of embolic coils comprising complex and WAVE shape properties with varying levels of softness to promote dense packing and durable long-term occlusion. We present the final analysis of 997 patients at 68 U.S./ Canada sites with up to $1-y r$ follow-up in the SMART registry to assess the utility of the SMART COIL System in the treatment of intracranial aneurysms and other malformations.

Materials and Methods The SMART registry is a prospective, multi-center registry assessing the embolization of neurovascular lesions using the Penumbra SMART COIL System. Procedures must employ $\geq 75 \%$ of SMART, PC400, or POD coils to meet inclusion criteria. SMART registry endpoints included retreatment rates through 1-yr ( $\pm 6-\mathrm{mo})$ follow-up, procedural device-related serious adverse events (SAE), and the ability to achieve adequate occlusion at immediate postprocedure.

Results This analysis of 997 patients $(72.1 \%$ female; mean age $59.6 \pm 13.0 \mathrm{yr}$ ) included cerebral aneurysms (91.0\%, 907/ 997); arteriovenous malformations (1.1\%); fistulae (4.1\%); and other lesions (3.8\%). Aneurysms, of which 31.8\% were ruptured, were small $(\leq 10 \mathrm{~mm})$ in $85.3 \%(774 / 907)$ of patients, large (>10 $\mathrm{mm}$ to $25 \mathrm{~mm})$ in $14.4 \%$ (131/907), and giant $(>25 \mathrm{~mm})$ in $0.2 \%(2 / 907) ; 63.5 \%(555 / 874)$ of patients had wide-neck aneurysms (dome-to-neck ratio $<2$ or neck width $\geq 4 \mathrm{~mm}$ ).

For all lesions, median coil deployment time, defined as the time from the first coil deployed until the last coil detached, was $16.0 \mathrm{~min}$ (IQR 8.0-32.0), and median time of fluoroscopic exposure was $37.0 \mathrm{~min}$ (IQR 24.0-56.0). Stentassisted coiling was performed in $5.7 \%$ of patients, and balloon-assisted coiling was performed in $18.7 \%$ of patients. Median packing density (calculated for aneurysms only) was 29.1\% [IQR 21.0-38.8].

For aneurysms, Raymond Occlusion Class (RROC) I and II was achieved in $79.7 \%(719 / 902)$ of cases at immediate postprocedure and in $90.1 \%(643 / 714)$ at 1 -yr follow-up, with a recanalization rate of $12.8 \%(91 / 710)$ and a retreatment rate of $7.1 \%(52 / 733)$. In multivariate models, a large or giant aneurysm size (odds ratio $[\mathrm{OR}]=2.45, \mathrm{p}=0.0030$ ), balloonassisted coiling $(\mathrm{OR}=1.84, \mathrm{p}=0.0195)$, ruptured aneurysm status $(\mathrm{OR}=3.91, \mathrm{p}<0.0001)$, and post-procedural RROC III $(\mathrm{OR}=1.91, \quad \mathrm{p}=0.0180)$, were predictors of incomplete occlusion (RROC III) at 1-yr follow-up. Large or giant aneurysms $(\mathrm{OR}=2.05, \mathrm{p}=0.0426)$, smoking $(\mathrm{OR}=0.5, \mathrm{p}=0.0186)$, and balloon-assisted coiling $(\mathrm{OR}=2.21, \mathrm{p}=0.0111)$ were also predictive of retreatment through 1-yr follow-up.

For non-aneurysm lesions, complete angiographic occlusion was achieved in $85.2 \%(23 / 27)$ of lesions post-procedure, with a recanalization rate of $6.1 \%(3 / 49)$ and a retreatment rate of $1.9 \%(1 / 53)$ at 1 -yr follow-up.

Overall, procedural device-related serious adverse events (SAE) were observed in 2.6\% (26/997) of subjects.

Conclusion The final results of the SMART Registry, a prospective registry with 997 subjects, demonstrate that the SMART COIL System achieves safe and adequate embolization in a wide variety of neurovascular lesions with low retreatment rates over 1 yr. Large aneurysm size and balloon-assisted coiling were predictive of incomplete occlusion at 1-yr and retreatment through 1-yr follow-up.

Disclosures A. Spiotta: None. M. Park: None. R. Bellon: None. B. Bohnstedt: None. C. Schirmer: None. R. DeLeacy: None. D. Fiorella: None. B. Woodward: None. B. Baxter: None. S. Kale: None. O. Zaidat: None. P. Sunenshine: None. A. Yoo: None. M. Kabbani: None. K. Liu: None. R. Starke: None. A. Reeves: None. K. Snyder: None. T. Sivapatham: None. T. Dumont: None.

\section{0-014 INTRAVASCULAR HIGH FREQUENCY OPTICAL COHERENCE TOMOGRAPHY GUIDED WEB ANEURYSM EMBOLIZATION}

${ }^{1} \mathrm{Z}$ Vardar, ${ }^{1} \mathrm{R}$ King, ${ }^{1} \mathrm{~A}$ Kraitem, ${ }^{1} \mathrm{E}$ Langan, ${ }^{2} \mathrm{~L}$ Peterson, ${ }^{2} \mathrm{~B}$ Duncan, ${ }^{1} \mathrm{C}$ Raskett, ${ }^{1} \mathrm{~V}$ Anagnostakou, ${ }^{1} \mathrm{M}$ Gounis*, ${ }^{1} \mathrm{~A}$ Puri, ${ }^{1} \mathrm{G}$ Ughi. ${ }^{1}$ Radiology, University of Massachusetts, Worcester, MA; ${ }^{2}$ RandD, Gentuity LLC, Sudbury, MA

\subsection{6/neurintsurg-2020-SNIS. 14}

Introduction High Frequency Optical Coherence Tomography $(\mathrm{HF}-\mathrm{OCT})^{1}$ is an intra-vascular imaging technique to assess device-vessel interactions and neointimal tissue growth at unprecedented spatial resolution $(\sim 10 \mu \mathrm{m})$. In this study, we tested the hypothesis that an adequately deployed (as visualized by HF-OCT) Woven EndoBridge (WEB, Microvention, Aliso Viejo, CA) will lead to a higher aneurysm occlusion rate at 12-week follow-up in an animal model of aneurysms.

Methods Elastase-induced rabbit aneurysms $(n=24)$ were treated with the WEB device. HF-OCT (Vis-M; Gentuity LLC, Sudbury MA) and DSA were performed after WEB deployment and repeated at 4,8 , and 12 weeks. Protrusion and malapposition were binary coded (0- present, 1 - absent; 0- malapposed, 1- neck apposition $>50 \%$ ), respectively, on HF-OCT and DSA. A device was considered adequately deployed if it was scored as 1 on both metrics. Aneurysm healing on DSA was interpreted using the 4-point WEB occlusion score (WOS) ${ }^{2}$; with A-B considered a positive outcome. HF-OCT images acquired at 12 weeks were analyzed and neointimal coverage quantified. Scanning electron microscopy (SEM) was performed of the explanted specimens.

Results Discrepancy between HF-OCT and DSA was found: HF-OCT classified as adequately deployed a total of 5 cases, whereas 8 cases were classified as adequately deployed by DSA images. Acceptable WOS grade at 12 weeks was seen in $21 \%$ of cases $(n=5): 80 \%$ of those cases $(n=4)$ were classified as adequately deployed based by HF-OCT; whereas only $60 \%$ of those cases $(n=3)$ classified adequate by DSA. A significant 